\title{
Failed Weaning from Mechanical Ventilation and Cardiac Dysfunction
}

\author{
Jahan Porhomayon, ${ }^{1}$ Peter Papadakos, ${ }^{2}$ and Nader D. Nader ${ }^{3}$ \\ ${ }^{1}$ VA Western New York Healthcare System, Division of Critical Care Medicine, Department of Anesthesiology and Medicine, \\ Buffalo School of Medicine and Biomedical Sciences, The State University of New York, Buffalo, NY 14215, USA \\ ${ }^{2}$ Strong Memorial Hospital, University of Rochester, Rochester, NY 14642, USA \\ ${ }^{3}$ VA Western New York Healthcare System, Division of Cardiothoracic Anesthesia and Pain Medicine, Department of Anesthesiology, \\ Buffalo School of Medicine and Biomedical Sciences, The State University of New York, Buffalo, NY 14215, USA
}

Correspondence should be addressed to Jahan Porhomayon, jahanpor@buffalo.edu

Received 20 June 2012; Accepted 3 August 2012

Academic Editor: Zsolt Molnar

Copyright ( $) 2012$ Jahan Porhomayon et al. This is an open access article distributed under the Creative Commons Attribution License, which permits unrestricted use, distribution, and reproduction in any medium, provided the original work is properly cited.

\begin{abstract}
Failure to transition patient from controlled mechanical ventilation to spontaneous breathing trials (SBTs) in a timely fashion is associated with significant morbidity and mortality in the intensive care unit. In addition, weaning failures are common in patients with limited cardiac reserves. Recent advances in cardiac echocardiography and laboratory measurement of serum biomarkers to assess hemodynamic response to SBT may provide additional information to guide clinicians to predict weaning outcome.
\end{abstract}

\section{Introduction}

Weaning critically ill patients from mechanical ventilation (MV) is a gradual and challenging process. Discontinuation of MV should be considered when patient is able to follow commands and maintain appropriate minute ventilation. In addition, protective airway reflexes should be intacts and patient clinical status must have improved. Clinical bedside assessment tools are crucial during the weaning trial (WT) so that ventilator requirements are met as the disease course is corrected. In April 2005, an international consensus conference sponsored by five major scientific societies was held in Budapest, Hungary to provide recommendations regarding the management of weaning process. The main recommendations were as follows: weaning should be considered as early as possible, patients should be divided to three categories (simple, difficult, prolonged weaning), a spontaneous breathing trial (SBT) is the major diagnostic test to determine whether patients can be successfully extubated, the initial trial should last 30 minutes and consist of either tracheal tube (T-Piece) breathing or low levels of pressure support, pressure support or assist-control ventilation modes should be favored in patients failing an initial trial/trials, and noninvasive ventilation techniques should be considered in selected patients to shorten the duration of intubation but should not be routinely used as a tool for extubation failure [1].

In general, mechanical weaning parameters are poor at predicting weaning success because they do not take into account cardiac reserves [2]. Therefore it is necessary for clinicians to understand the cardiovascular response to weaning trials and utilize the available tools to guide the wean team.

\section{Physiology of Spontaneous Breathing Trials}

MV weaning trial can be compared to a cardiac stress test where spontaneous ventilation is a form of an exercise [2], and therefore hemodynamic compromise can occur during weaning process in critically ill patients. The immediate transition from positive pressure mechanical ventilation to spontaneous ventilation may generate significant cardiopulmonary alterations based on the mode of weaning selected, particularly in individuals with preexisting cardiac dysfunction. Consideration of baseline cardiac reserve may be an important factor in the selection of an appropriate mode of spontaneous ventilation following controlled MV [3]. 
There are many studies reflecting on the concept of breathing as an exercise [4-8]. The important study by Mohsenifar et al. looked at the gastric intramural $\mathrm{pH}$ as a predictor of success or failure in weaning patients from mechanical ventilation. He concluded that gastrointestinal acidosis may be an early sign of weaning failure resulting from low cardiac output states [9]. The study by Jubran et al. looked at mixed venous oxygen saturation $\left(\mathrm{SvO}_{2}\right)$ monitoring for assessing hemodynamic performance and global tissue oxygenation in determining weaning outcome. He demonstrated that ventilator-supported patients who failed a trial of spontaneous breathing developed a progressive decrease in $\mathrm{SvO}_{2}$ caused by the combination of a relative decrease in $\mathrm{O}_{2}$ transport and an increase in $\mathrm{O}_{2}$ extraction by the tissues [10].

The original study by Lemaire and colleagues looked at the hemodynamic effects of rapidly weaning patients from MV with severe chronic obstructive pulmonary disease (COPD) and cardiovascular disease who were recovering from acute cardiopulmonary decompensation. They showed that during spontaneous breathing trials on T-piece, majority of patients demonstrated marked increase in the pulmonary artery occlusion pressure, left ventricular end diastolic volume index, and controlled MV had to be resumed [11]. Similarly, Routsi et al. demonstrated that nitroglycerin infusion can expedite the weaning by restoring weaninginduced cardiovascular compromise in COPD patients [12]. The explanation for Lemaire finding is related to the changes in lung volumes.

It is important to recognize the physiologic effect of lung volumes and intrathoracic pressures (ITPs) on ventilation. Low lung volumes result in alveolar collapse and hypoxia, stimulating pulmonary vasomotor tone by the process of hypoxic pulmonary vasoconstriction [13]. In contrast, at high lung volumes the increase in pulmonary vascular resistance [14] and right ventricular afterload is largely due to increase in transpulmonary pressure [15] (Figure 1). Brower et al. and other investigators concluded that during spontaneous breathing trials (SBTs), hyperventilation can lead to increase in pulmonary vascular resistance [14], and patients with lung disease are more at risk for hyperinflation and hemodynamic changes $[16,17]$. Pinsky also demonstrated that changes in lung volume alter autonomic tone and pulmonary vascular resistance (PVR), and high lung volumes compress the heart in the cardiac fossa. Hyperinflation increases PVR and pulmonary artery pressure, impeding right ventricular ejection fraction $[18,19]$.

Similarly, variations in intrathoracic pressure generated by different ventilator weaning modes may significantly affect hemodynamic and cardiovascular stability [20]. Heart is an intrathoracic organ; hence any changes in intrathoracic pressures (ITPs) can lead to changes in left ventricular (LV) afterload and venous return [21, 22]. In 1984, Pinsky elegantly demonstrated in his study that spontaneous inspiratory efforts decrease intrathoracic pressure (ITP). Decreases in ITP will augment venous return and impede LV ejection and increase intrathoracic blood volume. Since diaphragmatic descent increases intra-abdominal pressure, these combined effects cause decreased right atrial pressure and increased venous pressure in the abdomen, markedly

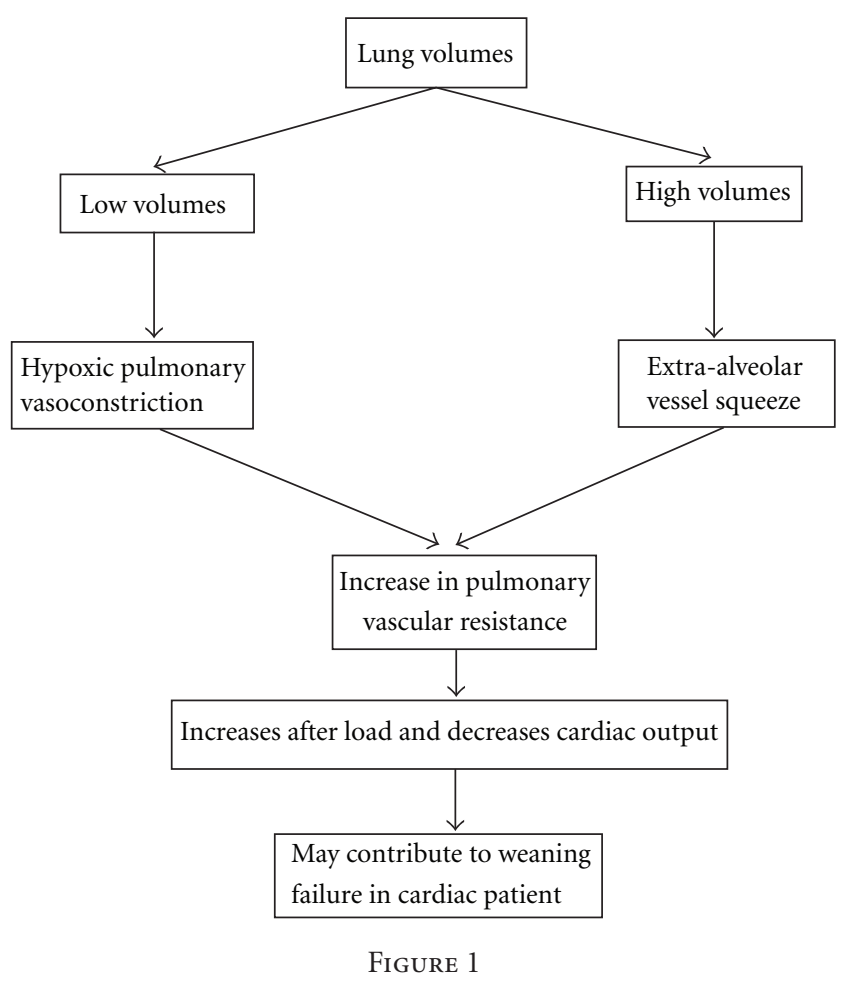

increasing the pressure gradient for systemic venous return [23]. Furthermore, the greater the decrease in ITP, the greater the increase in LV afterload for a constant arterial pressure, and right ventricle stroke output increases [24]. Pulmonary edema from negative pressure effect in patient breathing through the narrow endotracheal tube could also contribute to lower ITP.

It is now known that loaded spontaneous inspiration leads to increase in venous return and possible decompensation to heart failure or pulmonary edema [25-27]. Other investigators have similarly shown that increases in intrathoracic pressure increase right atrial pressure and decrease transmural LV systolic pressure. This will reduce the pressure gradients for venous return and LV ejection resulting in lower thoracic blood volume. This hemodynamic alteration generates a change in autonomic tone, so that cardiac output could be maintained. Therefore, individuals with autonomic and/or cardiovascular dysfunction may not be capable of this type of response and may fail to successfully wean from mechanical ventilation [20] (Figure 2).

\section{Assessment of Cardiac Function during Weaning}

3.1. B-Type Natriuretic Peptide. B-type natriuretic peptide levels are quantitative markers of cardiac stress and heart failure that summarize the degree of systolic and diastolic left ventricular dysfunction [28]. Initial observational pilot studies have addressed several potential indications in the intensive care unit: identification of cardiac dysfunction, diagnosis of hypoxic respiratory failure, risk stratification in severe sepsis and septic shock, evaluation of patients with shock [29], 


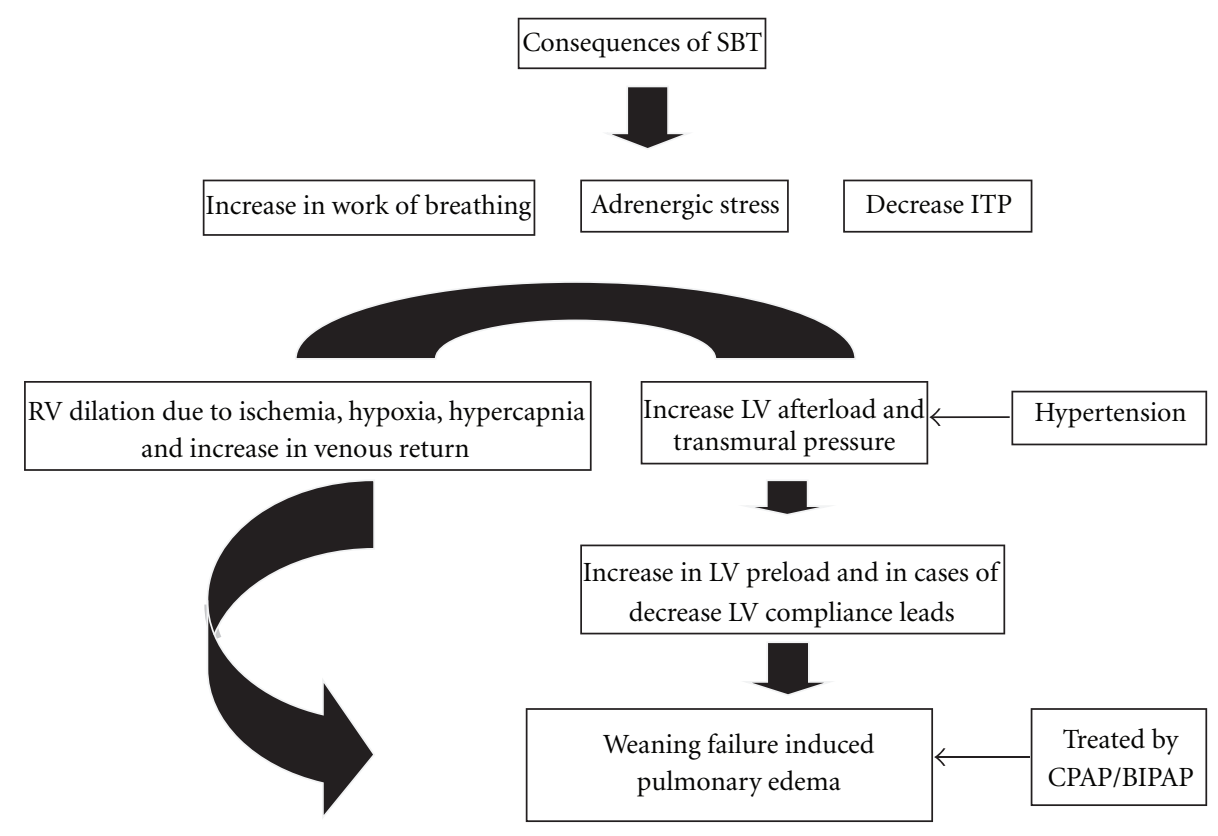

FIgure 2: SBT: Spontaneous Breathing Trials, ITP: Intra-thoracic Pressure, CPAP: Continuous Positive Pressure Therapy, BIPAP: Bi-level Positive Pressure, LV: Left Ventricle, RV: Right Ventricle.

and weaning from mechanical ventilation [30]. B-type natriuretic peptide (BNP) is a cardiac neurohormone synthesized in the cardiac ventricles. It is released as a pre-pro-BNP peptide of 134 amino acids and is cleaved into pro-BNP (108 amino acids) and a signal peptide of 26 amino acids. Pro-BNP is subsequently cleaved into BNP (32 amino acids) and the inactive N-terminal pro-BNP peptide (NT-pro-BNP; 76 amino acids [Figure 3]) [31, 32]. The release of BNP into the circulation is directly proportional to the ventricular expansion and volume overload of the ventricles and therefore reflects the decompensated state of the ventricles $[33,34]$. The effects of BNP-vasodilatation, natriuresis, and diuresis-lead to some improvement of the loading conditions of the failing heart.

Multiple studies have addressed the question of whether BNP or NT-pro-BNP could be used to identify patients who fail to wean for cardiac reasons [33-40]. The study by Zapata et al. was a prospective observational study of $100 \mathrm{MV}$ patients [41]. All patients underwent spontaneous breathing trials over 48 hours and were assessed by transthoracic echocardiography, pulmonary artery catheter and BNP and NT-pro-BNP. They concluded that B-type natriuretic peptides, particularly BNP, can predict weaning failure due to heart failure (HF) before an SBT. Increases in natriuretic peptides during SBT are diagnostic of $\mathrm{HF}$ as the cause of weaning failure. BNP performs better than NT-pro-BNP in prediction and diagnosis of HF. The cut-off values using receiver operating (ROC) curve analyses to predict HF were $263 \mathrm{ng} / \mathrm{L}$ for BNP $(P<0.001)$ and $1,343 \mathrm{ng} / \mathrm{L}$ for NT-pro-BNP $(P=$ 0.08). Mekontso-Dessap et al. [37] showed BNP levels after diuretic therapy were lower in patients with weaning success ( $517 \mathrm{pg} / \mathrm{mL}$ versus $226 \mathrm{pg} / \mathrm{mL}$ ). Grasso et al. [40] used Nterminal pro-BNP to detect acute cardiac dysfunction during weaning failure in difficult-to-wean patients with chronic obstructive pulmonary disease. He showed that plasma levels of NT-pro-BNP increased significantly at the end of the spontaneous breathing trial only in patients with acute cardiac dysfunction (median 12,733, interquartile range $16,456 \mathrm{pg} / \mathrm{mL}, P<0.05)$. Chien et al. [36] used the median BNP levels after the $2 \mathrm{hr}$ SBT showing BNP levels were 461 (168-1202) pg/mL, 418 (218-1085) pg/mL, and 224 $(112-660) \mathrm{pg} / \mathrm{mL}$ in the SBT failure, extubation failure, and extubation success groups, respectively. Gerbaud et al. [38] prospectively evaluated 44 patients with echocardiography and NT-pro-BNP. NT-pro-BNP levels (8199 (3106-10949) versus $4200(1855-7125) \mathrm{pg} / \mathrm{mL}, P=0.004)$ increased significantly in those who failed the SBT.

3.2. Echocardiography. There is growing indication to advocate that transthoracic echocardiography (TTE) should be used to categorize the cardiac origin of respiratory weaning failure. The study by Gerbaud et al. looks at the weaning trials in congestive heart failure patient by analysis of the mitral Doppler inflow $E$ velocity to annular tissue Doppler $E_{a}$ wave velocity $\left(E / E_{a}\right)$ ratio measurement. Even though he concluded that TTE could not predict the outcome of SBT, he noticed cardiac index increased significantly at end-SBT in patients who passed [38]. In contrast, the study by Moschietto et al. in 68 patients on MV over 48 hours proved that measurement of the $E / E_{a}$ ratio with TTE could predict weaning failure. Diastolic dysfunction with relaxation impairment was strongly associated with weaning failure. Additionally, the impossibility of enhancing the left ventricle relaxation rate during the SBT seemed to be the key factor of weaning failure. In contrast, the systolic dysfunction was not associated with weaning outcome [42]. Papanikolaou et al. evaluated 50 patients with Doppler echocardiography to predict outcome of weaning trials. The result indicated 
TABLE 1: Prediction of respiratory weaning outcomes.

\begin{tabular}{lcll}
\hline Author & Number & Study & Outcome \\
\hline Zapata et al. [41] & 100 & Prospective & BNP or pro-BNP \& ECHO predict WO \\
Gerbaud et al. [38] & 44 & Prospective & BNP or pro-BNP \& ECHO did not predict WO \\
Papaioannou et al. [7] & 42 & Prospective & Cardiorespiratory dynamics predict WO \\
Chien et al. [36] & 52 & Prospective & Percent change of less than 20\% in BNP predicts WO \\
Mekontso-Dessap et al. [37] & 102 & Prospective & Lower BNP levels before SBT may predicts WO \\
Moschietto et al. [42] & 68 & Prospective & ECHO predicts WO \\
Schifelbain et al. [44] & 24 & Prospective & ECHO did not predicts WO \\
Caille et al. [46] & 117 & Prospective & ECHO predicts WO \\
Grasso et al. [40] & 19 & Prospective & BNP predicts WO \\
\hline
\end{tabular}

ECHO: echocardiography, WO: weaning outcome, BNP: B-type natriuretic peptide.

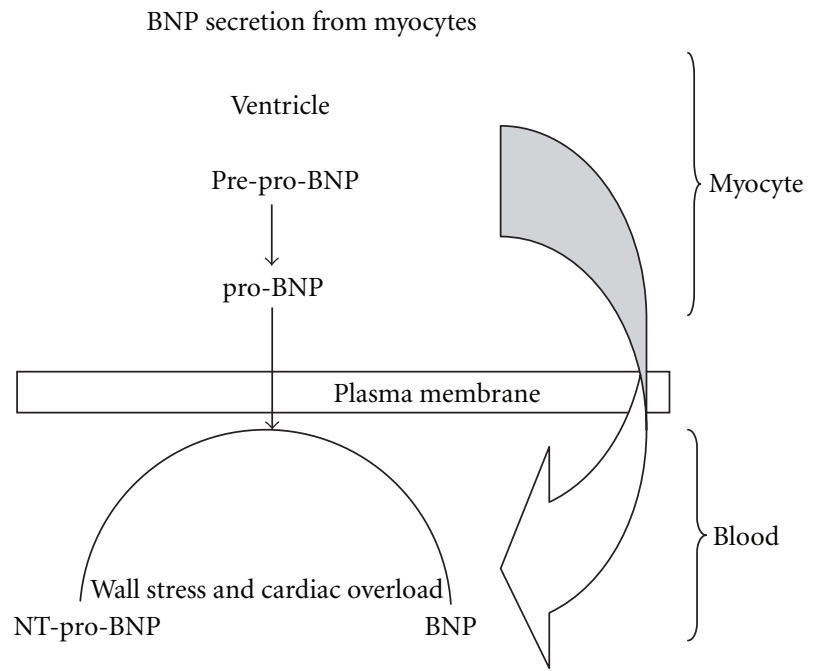

FIGURE 3: BNP: B-type natriuretic peptide, NT-pro-BNPL: Nterminal pro-B-type natriuretic peptide.

that LV diastolic dysfunction is significantly associated with weaning outcome in critically ill patients with preserved LV systolic function. An $E / E_{a}$ ratio greater than 7.8 may identify patients at high risk of weaning failure [43]. Schifelbain et al. conducted randomized crossover clinical trial of 24 patients to analyze changes in cardiac function, using Doppler echocardiogram, in critical patients during weaning from $\mathrm{MV}$. He used two different weaning methods: pressure support ventilation and T-tube. He did not find any differences between Doppler echocardiography and cardiorespiratory variables during pressure support ventilation and T-tube. However cardiac structures were smaller, isovolumetric relaxation time was larger, and oxygenation level was greater in successfully weaned patients [44]. It is probably safe to say that Doppler echocardiography has a place for assessment of weaning failure due to cardiac origin if performed routinely in the ICU. However, due to certain limitation relating to patient, it cannot be used in every patient [22, 45, 46] (Table 1).

3.3. Management of Weaning Failure from Cardiac Dysfunction. Therapeutic options should take into consideration the etiology of weaning failure. Weaning failure due to excessive preload should be treated with diuretic. It is important to rule out extra cardiac causes of weaning failure in such cases. Vasodilator therapy is indicated for weaning failure due to excessive afterload or myocardial ischemia. Additionally, alteration in ITP can be prevented by the use of CPAP/BIPAP (Figure 2). Noninvasive ventilation decreases cardiac stress load and should be utilized in weaning patients with poor cardiac reserves $[47,48]$. In fact, positive pressure therapy is now the standard of care for treating patients with acute pulmonary edema and decreases afterload [3, 19]. Using the same physiological concept, Marino and Langhelle et al. and others have introduced the concept of resistive loaded breathing to augment cardiac output during cardiopulmonary resuscitation [49-52].

\section{Conclusion}

Assessment and prediction of weaning failure from cardiac origin remain complicated. Current prediction models are difficult to implement clinically at bedside. Echocardiography remains a valuable tool to monitor respiratory weaning process and requires expertise in image interpretation. Additionally, the need for multiple assessments makes it difficult to implement echocardiography as a routine monitor in the intensive care setting. Serum BNP and NT-pro-BNP appear promising to identify patients with heart failure during weaning process. However, laboratory turnover time and the accepted cut-off values for HF pose a clinical challenge for data interpretation in the intensive care arena.

\section{Key Messages for Practicing Intensivists}

(i) Ischemic heart disease, valvular heart disease, systolic or diastolic dysfunction contributes to increase in cardiac load and weaning failure.

(ii) Extra demand on cardiac working load imposed by SBT may become apparent when transferring patient from positive to spontaneous ventilation.

(iii) Diuretic therapy may be considered for excessive preload.

(iv) Noninvasive positive pressure ventilation is beneficial for weaning-induced pulmonary edema. 
(v) Further cardiac evaluation is necessary if changes in natriuretic peptide levels are detected during SBT.

\section{Conflict of Interests}

Authors do not have any financial and personal relationships with other people or organizations that could inappropriately influence (bias) their work. Examples of potential conflicts of interest include employment, consultancies, stock ownership, honoraria, paid expert testimony, patent applications/registrations, and grants or other funding.

\section{References}

[1] J. M. Boles, J. Bion, A. Connors et al., "Weaning from mechanical ventilation," European Respiratory Journal, vol. 29, no. 5, pp. 1033-1056, 2007.

[2] M. R. Pinsky, "Breathing as exercise: the cardiovascular response to weaning from mechanical ventilation," Intensive Care Medicine, vol. 26, no. 9, pp. 1164-1166, 2000.

[3] S. K. Frazier, K. S. Stone, E. R. Schertel, D. K. Moser, and J. W. Pratt, "A comparison of hemodynamic changes during the transition from mechanical ventilation to T-piece, pressure support, and continuous positive airway pressure in canines," Biological Research for Nursing, vol. 1, no. 4, pp. 253-264, 2000.

[4] J. J. Kolkman, A. B. J. Groeneveld, F. G. Van Der Berg, J. A. Rauwerda, and S. G. M. Meuwissen, "Increased gastric pCO2 during exercise is indicative of gastric ischaemia: a tonometric study," Gut, vol. 44, no. 2, pp. 163-167, 1999.

[5] J. A. Otte, E. Oostveen, R. H. Geelkerken, A. B. J. Groeneveld, and J. J. Kolkman, "Exercise induces gastric ischemia in healthy volunteers: a tonometry study," Journal of Applied Physiology, vol. 91, no. 2, pp. 866-871, 2001.

[6] F. J. Hurtado, M. Berón, W. Olivera et al., "Gastric intramucosal $\mathrm{pH}$ and intraluminal $\mathrm{PCO} 2$ during weaning from mechanical ventilation," Critical Care Medicine, vol. 29, no. 1, pp. 70-76, 2001.

[7] V. E. Papaioannou, I. Chouvarda, N. Maglaveras, C. Dragoumanis, and I. Pneumatikos, "Changes of heart and respiratory rate dynamics during weaning from mechanical ventilation: a study of physiologic complexity in surgical critically ill patients," Journal of Critical Care, vol. 26, no. 3, pp. 262-272, 2011.

[8] B. Cabello, A. W. Thille, F. Roche-Campo, L. Brochard, F. J. Gómez, and J. Mancebo, "Physiological comparison of three spontaneous breathing trials in difficult-to-wean patients," Intensive Care Medicine, vol. 36, no. 7, pp. 1171-1179, 2010.

[9] Z. Mohsenifar, A. Hay, J. Hay, M. I. Lewis, and S. K. Koerner, "Gastric intramural $\mathrm{pH}$ as a predictor of success or failure in weaning patients from mechanical ventilation," Annals of Internal Medicine, vol. 119, no. 8, pp. 794-798, 1993.

[10] A. Jubran, M. Mathru, D. Dries, and M. J. Tobin, "Continuous recordings of mixed venous oxygen saturation during weaning from mechanical ventilation and the ramifications thereof," American Journal of Respiratory and Critical Care Medicine, vol. 158, no. 6, pp. 1763-1769, 1998.

[11] F. Lemaire, J. L. Teboul, L. Cinotti et al., "Acute left ventricular dysfunction during unsuccessful weaning from mechanical ventilation," Anesthesiology, vol. 69, no. 2, pp. 171-179, 1988.

[12] C. Routsi, I. Stanopoulos, E. Zakynthinos et al., "Nitroglycerin can facilitate weaning of difficult-to-wean chronic obstructive pulmonary disease patients: a prospective interventional nonrandomized study," Critical Care, vol. 14, no. 6, article no. R204, 2010.

[13] T. S. Hakim, R. P. Michel, and H. K. Chang, "Effect of lung inflation on pulmonary vascular resistance by arterial and venous occlusion," Journal of Applied Physiology, vol. 53, no. 5, pp. 1110-1115, 1982.

[14] R. G. Brower, J. Gottlieb, and R. A. Wise, "Locus of hypoxic vasoconstriction in isolated ferret lungs," Journal of Applied Physiology, vol. 63, no. 1, pp. 58-65, 1987.

[15] J. B. Howell, S. Permutt, D. F. Proctor, and R. L. Riley, "Effect of inflation of the lung on different parts of pulmonary vascular bed," Journal of Applied Physiology, vol. 16, pp. 71-76, 1961.

[16] N. A. Bergman, "Properties of passive exhalations in anesthetized subjects," Anesthesiology, vol. 30, no. 4, pp. 378-387, 1969.

[17] C. M. Conway, "Haemodynamic effects of pulmonary ventilation," British Journal of Anaesthesia, vol. 47, no. 7, pp. 761-766, 1975.

[18] M. R. Pinsky, "Instantaneous venous return curves in an intact canine preparation," Journal of Applied Physiology, vol. 56, no. 3, pp. 765-771, 1984.

[19] M. R. Pinsky, "Cardiovascular issues in respiratory care," Chest, vol. 128, no. 5, supplement 2, pp. 592S-597S, 2005.

[20] S. K. Frazier, D. K. Moser, and K. S. Stone, "Heart rate variability and hemodynamic alterations in canines with normal cardiac function during exposure to pressure support, continuous positive airway pressure, and a combination of pressure support and continuous positive airway pressure," Biological Research for Nursing, vol. 2, no. 3, pp. 167-174, 2001.

[21] A. J. Buda, M. R. Pinsky, and N. B. Ingels, "Effect of intrathoracic pressure on left ventricular performance," The New England Journal of Medicine, vol. 301, no. 9, pp. 453-459, 1979.

[22] B. Lamia, J. Maizel, A. Ochagavia et al., "Echocardiographic diagnosis of pulmonary artery occlusion pressure elevation during weaning from mechanical ventilation," Critical Care Medicine, vol. 37, no. 5, pp. 1696-1701, 2009.

[23] M. R. Pinsky, "Determinants of pulmonary arterial flow variation during respiration," Journal of Applied Physiology, vol. 56, no. 5, pp. 1237-1245, 1984.

[24] R. A. Bronicki, M. Herrera, R. Mink et al., "Hemodynamics and cerebral oxygenation following repair of tetralogy of fallot: the effects of converting from positive pressure ventilation to spontaneous breathing," Congenital Heart Disease, vol. 5, no. 5, pp. 416-421, 2010.

[25] J. Yu, J. F. Zhang, A. M. Roberts, L. C. Collins, and E. C. Fletcher, "Pulmonary rapidly adapting receptor stimulation does not increase airway resistance in anesthetized rabbits," American Journal of Respiratory and Critical Care Medicine, vol. 160, no. 3, pp. 906-912, 1999.

[26] A. M. Miro, U. Shivaram, and P. J. P. Finch, "Noncardiogenic pulmonary edema following laser therapy of a tracheal neoplasm," Chest, vol. 96, no. 6, pp. 1430-1431, 1989.

[27] C. E. Oswalt, G. A. Gates, and F. M. G. Holmstrom, "Pulmonary edema as a complication of acute airway obstruction," Journal of the American Medical Association, vol. 238, no. 17, pp. 1833-1835, 1977.

[28] R. Berger, D. Moertl, S. Peter et al., "N-terminal pro-B-type natriuretic peptideg, intensive patient management in addition to multidisciplinary care in chronic heart failure. A 3-arm, prospective, randomized pilot study," Journal of the American College of Cardiology, vol. 55, no. 7, pp. 645-653, 2010.

[29] N. I. Nikolaou, C. Goritsas, M. Dede et al., "Brain natriuretic peptide increases in septic patients without severe sepsis or 
shock," European Journal of Internal Medicine, vol. 18, no. 7, pp. 535-541, 2007.

[30] C. Mueller, A. Maisel, A. Mebazaa, and G. S. Filippatos, "The use of B-type natriuretic peptides in the intensive care unit," Congestive Heart Failure, vol. 14, no. 4, supplement 1, pp. 4345, 2008.

[31] F. Boomsma and A. H. Van Den Meiracker, "Plasma A- and Btype natriuretic peptides: physiology, methodology and clinical use," Cardiovascular Research, vol. 51, no. 3, pp. 442-449, 2001.

[32] M. Kuhn, "Molecular physiology of natriuretic peptide signalling," Basic Research in Cardiology, vol. 99, no. 2, pp. 76-82, 2004.

[33] R. Pirracchio, R. Salem, and A. Mebazaa, "Use of B-type natriuretic peptide in critically ill patients," Biomarkers in Medicine, vol. 3, no. 5, pp. 541-547, 2009.

[34] T. Principi, G. Falzetti, D. Elisei, A. Donati, and P. Pelaia, "Behavior of B-type natriuretic peptide during mechanical ventilation and spontaneous breathing after extubation," Minerva Anestesiologica, vol. 75, no. 4, pp. 179-183, 2009.

[35] F. Abroug and L. Ouanes-Besbes, "Detection of acute heart failure in chronic obstructive pulmonary disease patients: role of B-type natriuretic peptide," Current Opinion in Critical Care, vol. 14, no. 3, pp. 340-347, 2008.

[36] J. Y. Chien, M. S. Lin, Y. C. T. Huang, Y. F. Chien, C. J. Yu, and P. C. Yang, "Changes in B-type natriuretic peptide improve weaning outcome predicted by spontaneous breathing trial," Critical Care Medicine, vol. 36, no. 5, pp. 1421-1426, 2008.

[37] A. Mekontso-Dessap, N. De Prost, E. Girou et al., "B-type natriuretic peptide and weaning from mechanical ventilation," Intensive Care Medicine, vol. 32, no. 10, pp. 1529-1536, 2006.

[38] E. Gerbaud, M. Erickson, M. Grenouillet-Delacre, M. C. Beauvieux, P. Coste, C. Durrieu-Jais et al., "Echocardiographic evaluation and N-terminal pro-brain natriuretic peptide measurement of patients hospitalized for heart failure during weaning from mechanical ventilation," Minerva Anestesiol, vol. 78, no. 4, pp. 415-425, 2012.

[39] A. Mekontso-Dessap, L. Tual, M. Kirsch et al., "B-type natriuretic peptide to assess haemodynamic status after cardiac surgery," British Journal of Anaesthesia, vol. 97, no. 6, pp. 777$782,2006$.

[40] S. Grasso, A. Leone, M. De et al., "Use of N-terminal pro-brain natriuretic peptide to detect acute cardiac dysfunction during weaning failure in difficult-to-wean patients with chronic obstructive pulmonary disease," Critical Care Medicine, vol. 35, no. 1, pp. 96-105, 2007.

[41] L. Zapata, P. Vera, A. Roglan, I. Gich, J. Ordonez-Llanos, and A. J. Betbesé, "B-type natriuretic peptides for prediction and diagnosis of weaning failure from cardiac origin," Intensive Care Medicine, vol. 37, no. 3, pp. 477-485, 2011.

[42] S. Moschietto, D. Doyen, L. Grech, J. Dellamonica, H. Hyvernat, and G. Bernardin, "Transthoracic echocardiography with doppler tissue imaging predicts weaning failure from mechanical ventilation: evolution of the left ventricle relaxation rate during a spontaneous breathing trial is the key factor in weaning outcome," Critical Care, vol. 16, no. 3, article R81, 2012.

[43] J. Papanikolaou, D. Makris, T. Saranteas, D. Karakitsos, E. Zintzaras, A. Karabinis et al., "New insights into weaning from mechanical ventilation: left ventricular diastolic dysfunction is a key player," Intensive Care Medicine. In press.

[44] L. M. Schifelbain, S. R. R. Vieira, J. S. Brauner, D. M. Pacheco, and A. A. Naujorks, "Echocardiographic evaluation during weaning from mechanical ventilation," Clinics, vol. 66 , no. 1 , pp. 107-111, 2011.
[45] G. Voga, "Hemodynamic changes during weaning: can we assess and predict cardiac-related weaning failure by transthoracic echocardiography?" Critical Care, vol. 14, no. 4, article no. $174,2010$.

[46] V. Caille, J. B. Amiel, C. Charron, G. Belliard, A. VieillardBaron, and P. Vignon, "Echocardiography: a help in the weaning process," Critical Care, vol. 14, no. 3, article no. R120, 2010.

[47] Y. Kaneko, J. S. Floras, K. Usui et al., "Cardiovascular effects of continuous positive airway pressure in patients with heart failure and obstructive sleep apnea," The New England Journal of Medicine, vol. 348, no. 13, pp. 1233-1241, 2003.

[48] M. Ferrer, A. Esquìnas, F. Arancibia et al., "Noninvasive ventilation during persistent weaning failure: a randomized controlled trial," American Journal of Respiratory and Critical Care Medicine, vol. 168, no. 1, pp. 70-76, 2003.

[49] A. Langhelle, T. Strømme, K. Sunde, L. Wik, G. Nicolaysen, and P. A. Steen, "Inspiratory impedance threshold valve during CPR," Resuscitation, vol. 52, no. 1, pp. 39-48, 2002.

[50] B. S. Marino, D. Yannopoulos, G. Sigurdsson et al., "Spontaneous breathing through an inspiratory impedance threshold device augments cardiac index and stroke volume index in a pediatric porcine model of hemorrhagic hypovolemia," Critical Care Medicine, vol. 32, no. 9, supplement, pp. S398S405, 2004.

[51] T. P. Aufderheide, G. Nichol, T. D. Rea, S. P. Brown, B. G. Leroux, P. E. Pepe et al., "A trial of an impedance threshold device in out-of-hospital cardiac arrest," The New England Journal of Medicine, vol. 365, no. 9, pp. 798-806, 2011.

[52] K. G. Lurie, T. Zielinski, S. McKnite, T. Aufderheide, and W. Voelckel, "Use of an inspiratory impedance valve improves neurologically intact survival in a porcine model of ventricular fibrillation," Circulation, vol. 105, no. 1, pp. 124-129, 2002. 


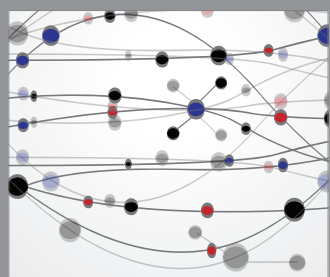

The Scientific World Journal
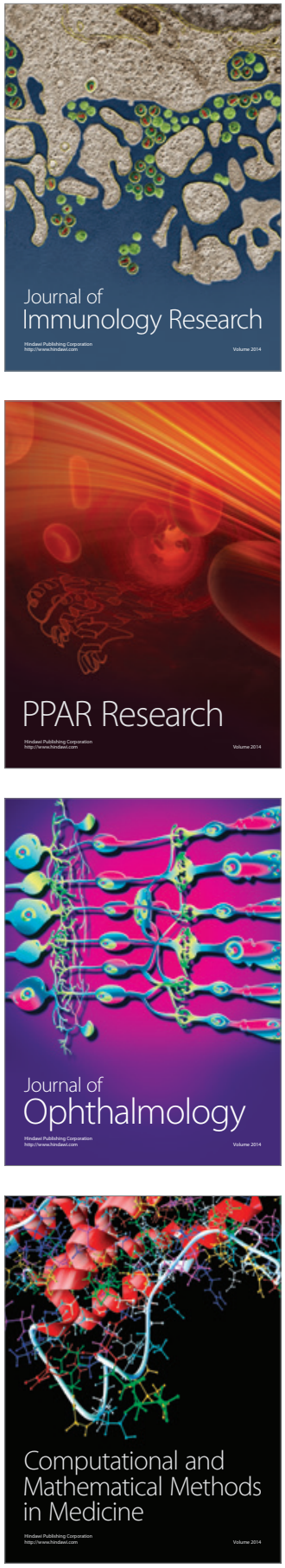

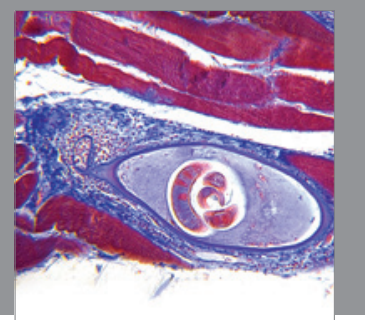

Gastroenterology

Research and Practice
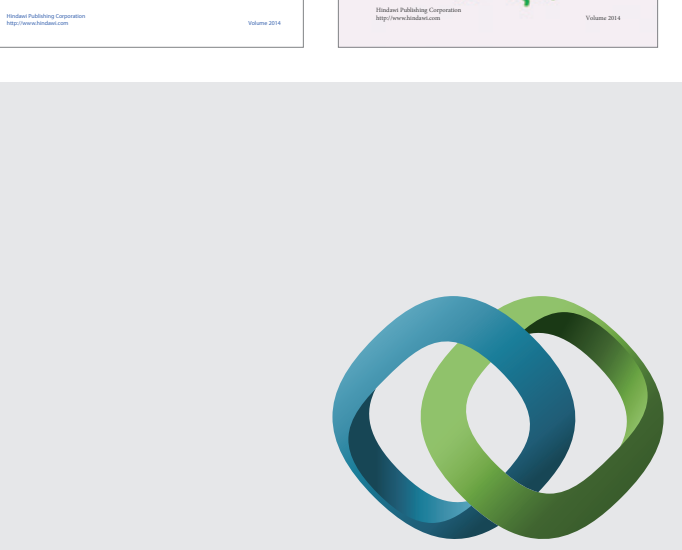

\section{Hindawi}

Submit your manuscripts at

http://www.hindawi.com
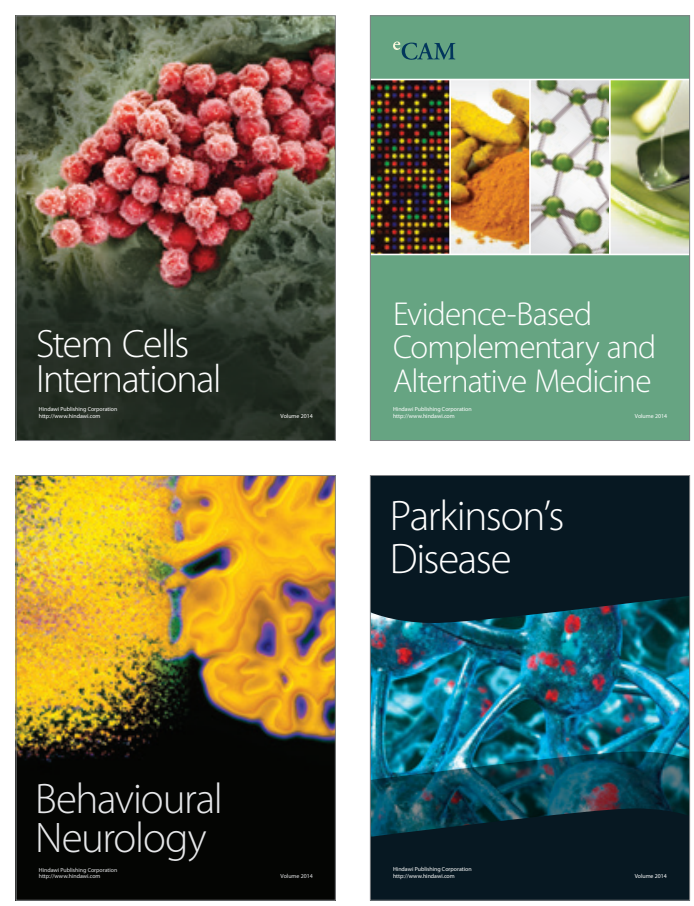

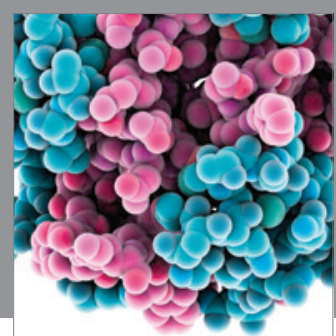

Journal of
Diabetes Research

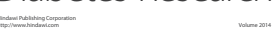

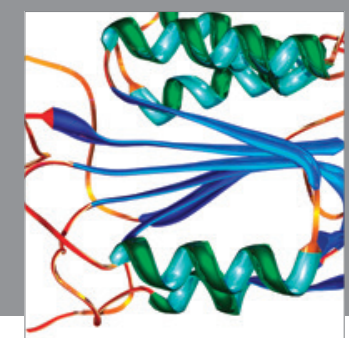

Disease Markers
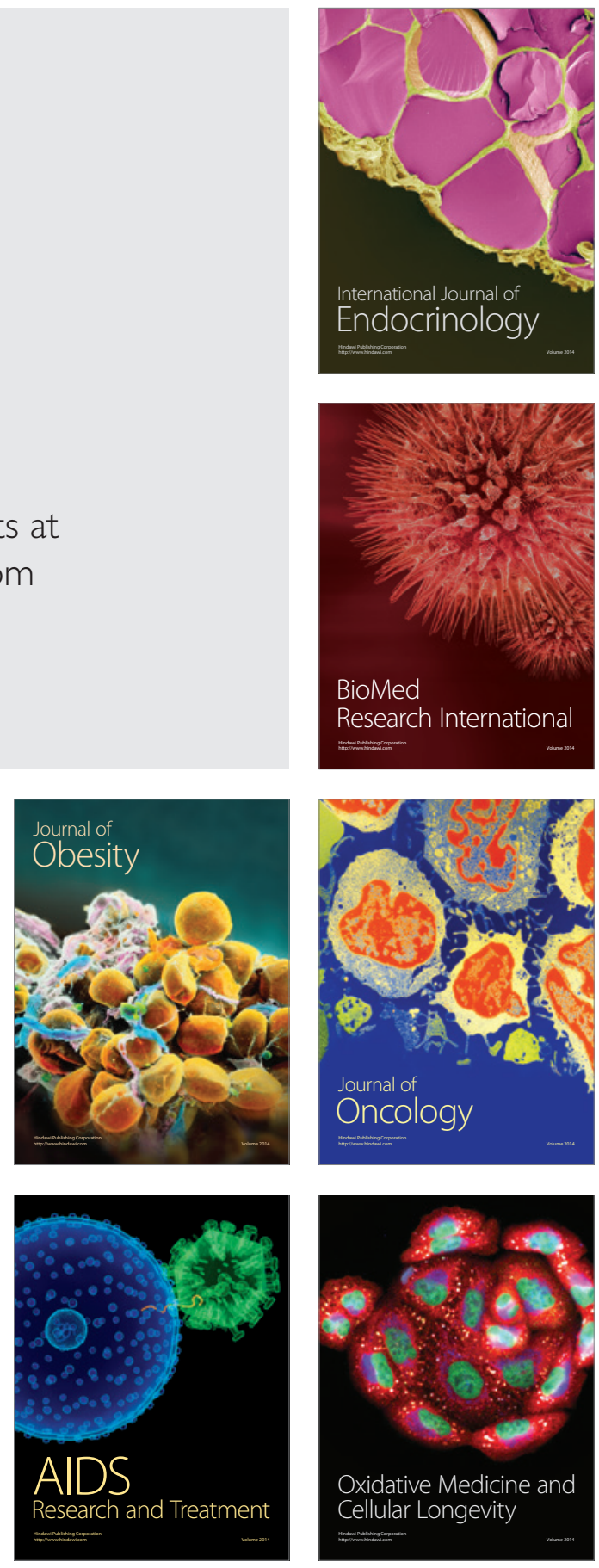